\title{
PERAN KETERIKATAN KERJA DAN KETERIKATAN ORGANISASIONAL TERHADAP KINERJA KARYAWAN
}

\author{
Siskawaty \\ chiasiska@gmail.com \\ Program Studi Magister Manajemen Universitas Tarumanagara \\ Rostiana, R \\ Fakultas Psikologi Universitas Tarumanagara
}

\begin{abstract}
This study aims to determine whether work engagement is divided into 3 dimensions namely vigor, dedication, and absorption and employee engagement which are divided into 7 dimensions, namely work environment, leadership, team and co-worker relations, training and career development, compensation, organizational policies, and workplace well-being has a role on employee performance which is divided into 5 dimensions, namely the quantity of work, quality of work, punctuality, attendance, and ability to cooperate. This research uses quantitative methods. The method of data collection uses a questionnaire distributed to 367 respondents who are employees of the Head Office at PT. $\mathrm{XYZ}$ with random sampling method. The analytical method used is multiple regression analysis using SPSS version 22.0. The results of the study show that the variables of work engagement and employee engagement have a role simultaneously or partially to the variable performance of employees with a 95\% confidence level. Work engagement and employee engagement have a total contribution of $63 \%$ to employee performance. Among these two variables, the most important role in employee performance is work engagement. Additional analysis shows that there are effects of differences in age groups and length of work on employee performance and educational background not related to the good or not of employee performance.
\end{abstract}

Abstrak : Penelitian ini bertujuan untuk mengetahui apakah keterikatan kerja yang terbagi menjadi 3 dimensi yaitu vigor, dedication, dan absorption dan keterikatan organisasional yang terbagi menjadi 7 dimensi yaitu lingkungan kerja, kepemimpinan, tim dan hubungan rekan kerja, pelatihan dan pengembangan karir, kompensasi, kebijakan organisasi, dan kesejahteraan kerja memiliki peran terhadap kinerja karyawan yang terbagi menjadi 5 dimensi yaitu kuantitas kerja, kualitas kerja, ketepatan waktu, kehadiran, dan kemampuan bekerjasama. Penelitian ini menggunakan metode kuantitatif. Metode pengumpulan data menggunakan kuesioner yang disebar pada 367 responden yang adalah karyawan Kantor Pusat di PT. XYZ dengan metode random sampling. Metode analisis yang digunakan adalah analisis regresi ganda menggunakan SPSS versi 22.0. Hasil penelitian menunjukkan bahwa variabel keterikatan kerja dan keterikatan organisasional memiliki peran secara simultan maupun secara parsial terhadap variabel kinerja karyawan dengan tingkat keyakinan 95\%. Keterikatan kerja dan keterikatan organisasional memiliki kontribusi total sebesar $63 \%$ terhadap kinerja karyawan. Di antara kedua variabel tersebut, yang paling memiliki peran terhadap kinerja karyawan adalah keterikatan kerja. Analisa tambahan menunjukkan bahwa terdapat pengaruh perbedaan golongan usia dan lama bekerja terhadap kinerja karyawan dan latar belakang pendidikan tidak berhubungan terhadap baik atau tidaknya kinerja karyawan.

Keyword : Keterikatan Kerja, Keterikatan Organisasional, Kinerja Karyawan 


\section{PENDAHULUAN}

Dalam menghadapi persaingan yang ketat di era globalisasi saat ini, perusahaan harus bisa mempertahankan aset-aset yang dimilikinya agar mampu bersaing dengan perusahaan lainnya, salah satu aset yang tidak luput dari perhatian adalah sumber daya manusia. Sumber daya manusia (SDM) merupakan aset perusahaan yang sangat penting dikarenakan betapapun majunya teknologi yang digunakan, atau seberapa banyak dana yang dipersiapkan tidak akan menjadi bermakna tanpa adanya sumber daya manusia yang profesional (Tjutju, 2008). Perusahaan apapun memerlukan sumber daya manusia untuk mencapai tujuannya. Melalui pengelolaan sumber daya manusia yang baik, perusahaan akan mempunyai sumber daya manusia yang handal. Sumber daya manusia yang handal yang dimiliki perusahaan akan mampu mewujudkan potensi perusahaan semaksimal mungkin. Agar sumber daya manusia bekerja dengan maksimal, maka karyawan harus memiliki keterikatan dengan perusahaan (Gallup, 2004).

Keterikatan karyawan telah dianggap sebagai pengantar kesuksesan bisnis di pasar yang kompetitif seperti saat ini dan salah satu faktor penentu dalam kesuksesan organisasional (Lockwood, 2007). Ketika karyawan terikat, secara otomatis mereka akan meningkatkan kinerjanya selaras dengan goal yang ingin dicapai oleh perusahaan. Karyawan yang memiliki tingkat work engagement (keterikatan kerja) yang tinggi akan menunjukan performa terbaik mereka. Hal ini karena karyawan tersebut menikmati pekerjaan yang mereka lakukan. Dalam persaingan yang ketat saat ini, perusahaan terus bersaing untuk mendapatkan karyawan yang memiliki potensi yang tinggi.

Selain itu, employee engagement (keterikatan organisasional) juga menjadi salah satu issue dalam kajian manajemen sumber daya manusia, karena memberikan banyak manfaat bagi perusahaan. Keterikatan organisasional merupakan kontributor yang sangat penting dari keberhasilan suatu perusahaan (Ayers, 2006 dalam Pillai, 2013). Karyawan yang engaged akan memiliki keinginan untuk terikat yang menimbukan gairah terhadap pekerjaanya, bersedia untuk mengorbankan lebih banyak tenaga dan waktu demi pekerjaannya, dan menjadi lebih proaktif dalam mencapai tujuan pekerjaanya (Macey et al., 2009).

Tujuan dari penelitian ini adalah : (1) Untuk mengetahui dan menganalisa apakah terdapat peran keterikatan kerja terhadap kinerja karyawan. (2) Untuk Mengetahui dan menganalisa apakah terdapat peran keterikatan organisasional terhadap kinerja karyawan. (3) Untuk mengetahui dan menganalisa apakah keterikatan kerja atau keterikatan organisasional yang memiliki peran lebih besar terhadap kinerja karyawan.

\section{KAJIAN TEORI}

\section{Keterikatan Kerja}

Keterikatan kerja didefinisikan oleh Schaufeli dan Bakker (2003) sebagai suatu kondisi pikiran yang positif terkait pekerjaan. Kahn (1990) menyebutkan bahwa dalam engagement, seseorang bekerja dan mengekspresikan dirinya secara fisik, kognitif, dan emosi selama mereka bekerja. Schaufeli dan Bakker (2003) menyebutkan bahwa seseorang yang memiliki keterikatan kerja akan menunjukkan level energi yang tinggi, merasa pekerjaan yang dilakukan berarti dan signifikan, merasa tertantang dengan tugas-tugas yang diberikan, memiliki level konsentrasi yang tinggi, dan selalu antusias serta senang ketika mengerjakan tugasnya.

\section{Keterikatan Organisasional}

Keterikatan orgnaisasional merupakan keadaan psikologis di mana karyawan merasa berkepentingan dalam keberhasilan perusahaan dan termotivasi untuk meningkatkan kinerja 
ke tingkat yang melebihi job requirement yang diminta (Mercer, dikutip oleh Carpenter \& Wyman, 2007:1). Lebih lanjut, Mercer (dikutip oleh Carpenter \& Wyman, 2007:1) menyatakan keterikatan organisasional dianggap sebagai sesuatu yang dapat memberikan perubahan pada individu, tim, dan perusahaan.

\section{Kinerja Karyawan}

Menurut Mathis \& Jakson (2007), kinerja karyawan adalah apa yang dilakukan dan tidak dilakukan oleh karyawan. Kinerja karyawan mempengaruhi keberlangsungan perusahaan tersebut dalam mencapai tujuan perusahaan. Kinerja karyawan yang baik dapat memberikan keuntungan bagi perusahaan, sedangkan kinerja yang buruk dapat menghasilkan kerugian bagi perusahaan. Kinerja yang buruk dapat di sebabkan oleh penurunan kinerja karyawan, dan hal ini dapat terlihat ketika karyawan tidak dapat menyelesaikan pekerjaan dengan target dan waktu yang di tentukan oleh perusahaan.

Peran Keterikatan Kerja dan Keterikatan Organisasional Terhadap Kinerja Karyawan

Karyawan yang dapat melakukan tugasnya dengan baik, mengerjakan pekerjaan dengan tangung jawab dan memiliki komitmen terhadap pekerjaannya merupakan karyawan yang memiliki keterikatan kerja. Karyawan yang berkomitmen merasakan nilai pentingnya mengintegrasikan tujuan individual dan perusahaan. Mas'ud (2004) mengemukakan bahwa keterikatan organisasional merupakan loyalitas karyawan terhadap perusahaan dan proses yang terus menerus terjadi dimana karyawan menunjukkan dan mengekspresikan perhatian atau hal yang penting terhadap perusahaan.

Dengan mengetahui tingkat engagement karyawan dan memeliharanya untuk tetap tinggi, maka secara umum perusahaan atau organisasi akan diuntungkan dengan berbagai hal seperti dapat mempertahankan dan meningkatkan produktivitas karyawan karena mereka merasa senang berkarya di perusahaan tersebut, membantu mempertahankan karyawan terbaik (karena mereka tidak mudah tergiur dengan tawaran perusahaan lain), dan membantu pencapaian target perusahaan.

Karyawan yang memiliki keterikatan akan termotivasi untuk memberikan usaha terbaiknya (Marciano, 2010). Robinson et al. (2004) menyatakan bahwa karyawan yang memiliki ikatan kuat dengan perusahaan akan meningkatkan performansi dalam pekerjaannya untuk keuntungan perusahaan (dalam Litile, 2006).

Berdasarkan paparan di atas, maka hipotesis penelitian adalah sebagai berikut :

H1 : Terdapat peran keterikatan kerja terhadap kinerja karyawan

H2 : Terdapat peran keterikatan organisasional terhadap kinerja karyawan

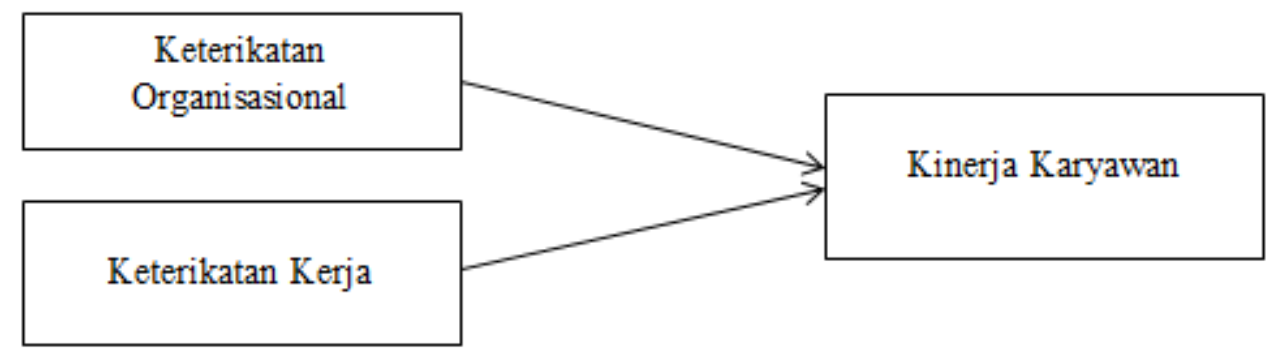

\section{METODE}

\section{Populasi, Teknik Pemilihan Sampel, dan Ukuran Sampel}

Populasi dalam penelitian ini adalah adalah karyawan Kantor Pusat di PT. XYZ. Metode pengambilan sampel dalam penelitian ini adalah teknik random sampling yang merupakan metode penetapan responden dengan memberikan peluang atau kesempatan kepada seluruh 
anggota populasi untuk menjadi sampel. Ukuran sampel yang digunakan dalam penelitian ini sebanyak 367 responden.

\section{Variabel dan Pengukuran}

Pada penelitian ini variabel keterikatan kerja dan keterikatan organisasional merupakan variabel bebas, dan kinerja karyawan merupakan variabel terikat.

Tabel 1. Variabel dan Pengukuran

\begin{tabular}{lcl}
\hline \multicolumn{1}{c}{ Variabel } & $\begin{array}{c}\text { Jumlah } \\
\text { Item }\end{array}$ & \multicolumn{1}{c}{ Sumber } \\
\hline 1. Keterikatan Kerja & 9 & $\begin{array}{l}\text { Schaufeli, W. B., Bakker, B. A \& Salanova, M. } \\
(2004) .\end{array}$ \\
& & Anitha J. (2014). \\
2. Keterikatan Organisasional & 22 & AGORA (2017). \\
3. Kinerja Karyawan & 15 & .
\end{tabular}

\section{Metode Analisa Data}

Metode analisis data yang digunakan untuk menjawab masalah penelitian ini adalah dengan analisis regresi ganda. Analisis regresi ganda digunakan untuk menguji pengaruh variabel independent secara bersama-sama (simultan) terhadap variabel dependent (Hadi, 2004: 18). Uji asumsi seperti uji normalitas, uji multikolineritas dan uji heterokedastisitas telah dilakukan sebelum analisis regresi berganda dilakukan dan hasilnya menunjukkan semua asumsi sudah terpenuhi. Taraf signifikansi yang digunakan dalam penelitian ini adalah 5\%. Pengujian dalam penelitian ini menggunakan program SPSS (Statistical Package for Social Science). Pada penelitian ini, pengujian untuk analisis data dilakukan dengan membagi menjadi 2 hipotesis, hipotesis pertama $(\mathrm{H} 1)$ yaitu menguji peran keterikatan kerja terhadap kinerja karyawan dan hipotesis kedua $(\mathrm{H} 2)$ yaitu menguji peran keterikatan organisasional terhadap kinerja karyawan.

\section{HASIL DAN PEMBAHASAN}

Tabel 2 berikut merupakan hasil uji validitas dan reliabilitas semua variabel penelitian:

Tabel 2. Hasil Uji Validitas dan Reliabilitas

\begin{tabular}{|c|c|c|c|}
\hline Variabel & Item & $\begin{array}{c}\text { Correcte } \\
\text { d item- } \\
\text { total } \\
\text { correlati } \\
\text { on }\end{array}$ & $\begin{array}{l}\text { Cronbac } \\
h \text { Alpha }\end{array}$ \\
\hline \multirow{9}{*}{$\begin{array}{c}\text { Keterikatan } \\
\text { Kerja }\end{array}$} & Di tempat kerja, saya merasa penuh dengan energi & 0,768 & \multirow{3}{*}{0,870} \\
\hline & $\begin{array}{l}\text { Saya merasa sangat kuat dan bertenaga mengerjakan } \\
\text { pekerjaan saya }\end{array}$ & 0,756 & \\
\hline & Saya terbenam dalam pekerjaan saya & 0,587 & \\
\hline & $\begin{array}{l}\text { Saya bangun tidur di pagi hari, saya merasa seperti pergi } \\
\text { bekerja }\end{array}$ & 0,756 & \multirow{3}{*}{0,729} \\
\hline & Saya merasa senang saat saya bekerja secara intensif & 0,587 & \\
\hline & Saat bekerja, saya terbawa dengan pekerjaan saya & 0,658 & \\
\hline & Saya antusias dengan pekerjaan saya & 0,752 & \multirow{3}{*}{0,771} \\
\hline & Pekerjaan saya menginspirasi saya & 0,756 & \\
\hline & Saya bangga dengan pekerjaan yang saya lakukan & 0,748 & \\
\hline $\begin{array}{l}\text { Keterikatan } \\
\text { Organisasio }\end{array}$ & $\begin{array}{l}\text { Tempat kerja saya mendukung semangat saya dalam } \\
\text { bekerja }\end{array}$ & 0,734 & 0,852 \\
\hline
\end{tabular}




\begin{tabular}{|c|c|c|c|}
\hline \multirow[t]{21}{*}{ nal } & $\begin{array}{l}\text { Fasilitas tempat kerja saya memuaskan sehingga saya } \\
\text { dapat bekerja dengan baik }\end{array}$ & 0,645 & \\
\hline & $\begin{array}{l}\text { Saya dapat fokus dalam pekerjaan karena lingkungan } \\
\text { mendukung }\end{array}$ & 0,733 & \\
\hline & $\begin{array}{l}\text { Pemimpin saya memberi inspirasi sehingga saya bekerja } \\
\text { dengan baik }\end{array}$ & 0,699 & \multirow{4}{*}{0,944} \\
\hline & Pemimpin saya mampu berkomunikasi dengan bawahan & 0,632 & \\
\hline & $\begin{array}{l}\text { Pemimpin saya mampu menjawab masalah saya dalam } \\
\text { bekerja }\end{array}$ & 0,627 & \\
\hline & $\begin{array}{l}\text { Pemimpin saya mampu memberi semangat untuk saya } \\
\text { dapat bekerja lebih baik }\end{array}$ & 0,692 & \\
\hline & $\begin{array}{l}\text { Saya mudah untuk bekerja karena saya mempercayai } \\
\text { rekan kerja saya }\end{array}$ & 0,712 & \multirow{4}{*}{0,910} \\
\hline & $\begin{array}{l}\text { Rekan kerja saya mendukung dalam menyelesaikan } \\
\text { pekerjaan }\end{array}$ & 0,638 & \\
\hline & $\begin{array}{l}\text { Saya mudah untuk bekerja karena memiliki hubungan } \\
\text { baik dengan rekan kerja saya }\end{array}$ & 0,727 & \\
\hline & $\begin{array}{l}\text { Komunikasi yang baik dengan rekan kerja membuat } \\
\text { saya giat bekerja }\end{array}$ & 0,748 & \\
\hline & Saya percaya diri dalam menyelesaikan pekerjaan saya & 0,702 & \multirow{3}{*}{0,710} \\
\hline & $\begin{array}{l}\text { Menurut saya penting bila terdapat jenjang karir dalam } \\
\text { perusahaan sehingga saya dapat lebih giat bekerja }\end{array}$ & 0,428 & \\
\hline & $\begin{array}{l}\text { Adanya kesempatan dari perusahaan untuk saya } \\
\text { bertumbuh dalam karir sehingga saya lebih giat bekerja }\end{array}$ & 0,665 & \\
\hline & $\begin{array}{l}\text { Gaji saya dalam bekerja memuaskan sehingga saya } \\
\text { dapat bekerja dengan baik }\end{array}$ & 0,428 & \multirow{2}{*}{0,728} \\
\hline & $\begin{array}{l}\text { Penghargaan yang diberikan dapat membuat saya lebih } \\
\text { giat bekerja }\end{array}$ & 0,665 & \\
\hline & $\begin{array}{l}\text { Saya menyadari bahwa peraturan membuat saya bekerja } \\
\text { lebih baik }\end{array}$ & 0,593 & \multirow{4}{*}{0,825} \\
\hline & Saya terbeban jika tidak menaati peraturan yang berlaku & 0,447 & \\
\hline & Saya menaati peraturan dengan sukarela tanpa paksaan & 0,727 & \\
\hline & $\begin{array}{l}\text { Saya menyadari untuk melakukan peraturan tanpa } \\
\text { disuruh atasan }\end{array}$ & 0,629 & \\
\hline & $\begin{array}{l}\text { Saya merasa sejahtera pada perusahaan tempat saya } \\
\text { bekerja }\end{array}$ & 0,610 & \multirow[b]{2}{*}{0,706} \\
\hline & $\begin{array}{l}\text { Saya dapat memiliki banyak pengalaman saat saya } \\
\text { bekerja di perusahaan sehingga saya ingin bekerja lebih } \\
\text { baik lagi }\end{array}$ & 0,786 & \\
\hline \multirow{6}{*}{$\begin{array}{l}\text { Kinerja } \\
\text { Karyawan }\end{array}$} & $\begin{array}{l}\text { Jumlah pekerjaan yang saya lakukan sesuai dengan } \\
\text { standar perusahaan }\end{array}$ & 0,653 & \multirow{3}{*}{0,797} \\
\hline & $\begin{array}{l}\text { Saya dapat menyelesaikan pekerjaan dengan jumlah } \\
\text { kesalahan yang sedikit }\end{array}$ & 0,658 & \\
\hline & $\begin{array}{l}\text { Saya dapat mengerjakan pekerjaan saya sesuai dengan } \\
\text { target }\end{array}$ & 0,674 & \\
\hline & $\begin{array}{l}\text { Saya memperhatikan mutu dan kualitas dalam pekerjaan } \\
\text { saya }\end{array}$ & 0,691 & \multirow{3}{*}{0,798} \\
\hline & $\begin{array}{l}\text { Saya dapat menyelesaikan pekerjaan saya dengan tepat, } \\
\text { rapi, dan teliti }\end{array}$ & 0,596 & \\
\hline & $\begin{array}{l}\text { Saya bertanggung jawab untuk menyelesaikan pekerjaan } \\
\text { sesuai dengan tugas yang diberikan }\end{array}$ & 0,612 & \\
\hline
\end{tabular}




\begin{tabular}{|c|c|c|}
\hline $\begin{array}{l}\text { Saya mengulang pekerjaan jika saya merasa itu tidak } \\
\text { sesuai dengan standar }\end{array}$ & 0,401 & \\
\hline Saya terbeban bila saya menunda pekerjaan & 0,577 & \multirow{3}{*}{0,748} \\
\hline $\begin{array}{l}\text { Saya merasa salah bila saya datang terlambat ke } \\
\text { perusahaan }\end{array}$ & 0,545 & \\
\hline Saya dapat menyelesaikan pekerjaan dengan tepat waktu & 0,517 & \\
\hline Saya terbeban jika bolos kerja & 0,520 & \multirow[b]{2}{*}{0,709} \\
\hline $\begin{array}{l}\text { Saya terbeban bila saya tidak masuk dan meninggalkan } \\
\text { pekerjaan saya }\end{array}$ & 0,415 & \\
\hline $\begin{array}{l}\text { Saya dapat bekerja sama dengan rekan karena } \\
\text { komunikasi yang baik }\end{array}$ & 0,668 & \multirow{3}{*}{0,932} \\
\hline $\begin{array}{l}\text { Saya memiliki hubungan yang baik dengan rekan kerja } \\
\text { sehingga mudah bekerja sama }\end{array}$ & 0,718 & \\
\hline $\begin{array}{l}\text { Saya mudah berkomunikasi dengan rekan kerja } \\
\text { sehingga dapat bekerjasama dengan baik }\end{array}$ & 0,734 & \\
\hline
\end{tabular}

Hasil uji validitas menunjukkan bahwa nilai corrected item total correlation semua butir pernyataan pada setiap variabel penelitian lebih besar dari 0,1020, dengan demikian dapat ditarik kesimpulan bahwa semua pernyataan pada semua variabel adalah valid. Sementara hasil dari pengujian reliabilitas seluruh variabel pada penelitian ini diperoleh nilai Cronbach's Alpha setiap variabel > 0,6, maka dapat disimpulkan bahwa seluruh dimensi yang digunakan dalam variabel penelitian ini reliabel.

Berdasarkan data yang telah dikumpulkan pada penelitian ini Sebagian besar responden dalam penelitian berjenis kelamin wanita $65 \%$, berusia 20 - 29 tahun sebesar $48,1 \%$, status menikah sebesar 52,7\%, berpendidikan terakhir S1 sebesar 82,2\%, dan lama bekerja > 5 tahun sebesar $61,1 \%$.

Pengujian dilakukan dengan analisis regresi ganda. Persamaan digunakan untuk mengetahui peran Keterikatan Kerja (X1) dan Keterikatan Organisasional (X2) terhadap Kinerja Karyawan (Y). Hasil analisis regresi ganda memiliki persamaan KINERJA KARYAWAN $=22,963+0,534$ KETERIKATAN KERJA $+0,237$ KETERIKATAN ORGANISASIONAL. Hasil uji-F menunjukkan bahwa nilai signifikan sebesar 0,000 (lebih kecil dari $\alpha=0,05$ ), maka dapat disimpulkan bahwa terdapat peran variabel keterikatan kerja dan keterikatan organisasional secara bersama-sama terhadap variabel kinerja karyawan dengan tingkat keyakinan 95\%. Hasil uji-t atau uji hipotesis menunjukkan bahwa secara parsial variabel keterikatan kerja dan keterikatan organisasional memiliki peran yang signifikan terhadap variabel kinerja karyawan. Nilai R-Square sebesar 0,63 yang memiliki arti bahwa keterikatan kerja dan keterikatan organisasional memiliki kontribusi sebesar $63 \%$ terhadap variabel kinerja karyawan sedangkan sisanya 37\% dapat dijelaskan oleh variabelvariabel lain yang tidak termasuk dalam penelitian.

Tabel 3. Hasil Pengujian Hipotesis

\section{HIPOTESIS}

KESIMPULAN

H1 Terdapat peran keterikatan kerja terhadap kinerja karyawan $\quad$ Diterima

H2 Terdapat peran keterikatan organisasional terhadap kinerja karyawan Diterima Berdasarkan hasil analisis regresi ganda, dapat disimpulkan bahwa nilai koefisien regresi $(\beta)$ yang paling memiliki peran terhadap kinerja karyawan adalah nilai $\beta$ pada keterikatan kerja sebesar 0,534 dan selanjutnya keterikatan organisasional dengan koefisien regresi ( $\beta$ ) 0,237. Dalam hal ini, jika variabel keterikatan kerja naik satu satuan, maka variabel kinerja karyawan akan mengalami kenaikan sebesar 0,534. Selanjutnya, apabila variabel keterikatan 
organisasional naik satu satuan, maka variabel kinerja karyawan juga akan mengalami kenaikan sebesar 0,237.

\section{PENUTUP}

\section{Simpulan}

Penelitian ini bertujuan untuk membuktikan bahwa keterikatan kerja dan keterikatan organisasional berperan terhadap kinerja karyawan. Hasil penelitian menunjukkan nilai signifikansi pada keterikatan kerja dan keterikatan organisasional sebesar 0,000 dan dapat disimpulkan bahwa keterikatan kerja dan keterikatan organisasional memiliki peran terhadap kinerja karyawan. Di antara kedua variabel tersebut, yang paling memiliki peran terhadap kinerja karyawan adalah keterikatan kerja.

\section{Saran}

Peneliti menyarankan agar PT. XYZ memperhatikan faktor keterikatan kerja pada karyawan karena semakin tingginya keterikatan kerja atau work engagement yang diberikan kepada PT. XYZ, hal tersebut dapat meningkatkan kinerja karyawan. Peneliti selanjutnya disarankan untuk melakukan penelitian dengan objek penelitian perusahaan yang berbeda. Hasil penelitian pun akan memberikan masukan yang lebih efektif bagi perusahaan untuk terus meningkatkan level keterikatan karyawannya. Diharapkan tulisan ini dapat menjadi salah satu referensi pendukung bagi peneliti selajutnya. Peneliti selanjutnya diharapkan lebih dapat menggali lebih dalam faktor- faktor serta berbagai dimensi yang ada dan disarankan untuk menambah variabel penelitian lain untuk memperkuat penelitian.

\section{DAFTAR PUSTAKA}

Anitha J. (2014). Determinants of employee engagement and their impact on employee performance. International Journal of Productivity and Performance Management, 63 (3), $308-323$.

AON-Hewitt. (2013). Trends in global employee engagement. December 14, 2017. http://www.-aon.com/attachments/humancapitalconsulting/2013_Trends_in_Global_Employee_En gagement_Report.pdf

Ayers, M. (2006). The relationship of ego identity status to effective leader behavior. - : Regent University.

Bakker, A. B. (2008). Building engagement in the workplace. In C. Cooper \& R. Burke (Eds.) (2008). The peak performing organization. London: Routledge.

Cataldo, P. (2011). Focusing on employee engagement: how to measure it and improve it. North Carolina: White Paper, UNC Kenan-Flagler Business School, UNC Executive Development.

Gallup. (2004). Study engaged employees inspire company innovation. Gallup Management Journal. December 14, 2017. http://gmj.gallup.com/content/24880/Gallup-StudyEngaged-EmployeesInspire-Company.aspx

Hadi, S. (2004). Metodologi research (3rd ed). Yogyakarta: Andi.

Handoko, T. H. (2001). Manajemen personalia dan sumber daya manusia. Yogyakarta: BPFE Yogyakarta.

Hasibuan, M. S. P. (2009). Manajemen: dasar, pengertian, dan masalah. Jakarta : PT. Bumi Aksara.

Kahn, W. A. (1990). Psychological conditions of personal engagement and disengagement at work. Academy of Management Journal, 33 (4), 692 - 724. 
Lockwood, N. (2007). Leveraging employee engagement for competitive advantage HR strategic role. SHRM Research, 1-11. Macey, W. H., William, dkk. (2009). Employee engagement: tools for analysis, practice and competitive advantages. Singapore: Willey Blackwell.

Macey, W. H., William. (2009). Employee engagement: tools for analysis, practice and competitive advantages. Singapore: Willey Blackwell.

Marciano, P. L., (2010). Carrots and sticks don't work: build a culture of employee engagement with the principles of respect. USA: McGraw Hill.

Mathis, Robert, L., \& Jackson, J. H. (2006). Human resource management, alih bahasa. Jakarta: PT. Salemba Empat.

Mas'ud, F. (2004). Survei diagnosis organisasional (konsep dan aplikasi). Semarang: Badan Penerbit Universitas Diponegoro.

Mathis, Robert, L,. \& Jackson, J. H. (2007). Human resources management. Thomson Learning.

Mercer, M. Carpenter, G. \& Wyman, O. (2007). Engaging employee to drive global business success. December 14, 2017.

Schaufeli, W \& Bakker, A. B. (2003). UWES (utrecht work engagement scale). Utrecht University: Occupational Health Psychology Unit.

Schwaratz, T., \& Porath, C. (2014). Why you hate work. Sunday Review. December 14, 2017. http://www.nytimes.com/2014/06/01/opinion/sunday/whyyouhate-work.html?_r=0

Tjutju, Y., \& Suwatno. (2008). Manajemen sumber daya manusia. Bandung: Alfabeta.

Wirawan. (2009). Evaluasi kinerja sumber daya manusia teori aplikasi dan penelitian. Jakarta: PT. Salemba Empat. 
